\title{
1 Atypical modulation of startle in women in face of aversive bodily sensations
} \\ Erik Ceunen, Johan W.S. Vlaeyen, Ilse Van Diest*
}

Research Group on Health Psychology, Department of Psychology, University of Leuven, Tiensestraat 102, Mailbox 3726, B-3000 Leuven, Belgium

\section{A R T I C L E I N F O}

\section{Article history:}

Received 29 August 2012

Received in revised form 10 January 2013

Accepted 19 March 2013

Available online $\mathrm{xxxx}$

\section{Keywords:}

Startle

Fear

Interoception

Homeostasis

Dyspnea

Hypothermia

\begin{abstract}
A B S T R A C T
Eye blink startle magnitude is assumed to be higher in threatening contexts. A scarce amount of studies suggest 22 Q3 that this does not hold true when startle is measured during perceived threats to homeostatic integrity. The 23 present study was set up to describe the startle response pattern to a selection of interoceptive stimuli. Female 24 subjects $(\mathrm{N}=36$ ) were exposed once to $90 \mathrm{~s}$ of continued (1) cold pain, (2) inhalation of a gas mixture of 25 $7.5 \% \mathrm{CO}_{2}$, and (3) breathing against an inspiratory and expiratory resistive load. Each stimulus was preceded 26 and followed by a 90 second period of rest, respectively labeled baseline and recovery. Even after correcting 27 eye blink startle responses for habituation, a decreased startle amplitude was evident during these stimuli. 28 Results suggest that startle amplitude during aversive stimulation is inversely correlated with perceived fearful- 29 ness for women, although further studies are necessary to corroborate this interpretation.

(C) 2013 Published by Elsevier B.V. 31

\section{Introduction}

Interoception, the perception of the state of the body, serves to maintain homeostasis and is closely linked to the experience of emotions (Craig, 2002). Interoceptive fear is the apprehension of bodily sensations (Shear et al., 1997) and can manifest itself following the perceived disruption of homeostasis or in the anticipation thereof (Furst and Cooper, 1970). The anticipated or perceived disruption of homeostasis that lies at the heart of interoceptive fear, can potentially relate to any part of the organisms' functioning, including gas-exchange and thermoregulation. Interoceptive fear includes fear of pain, as pain is a perception related to the body state, processed in a neural network that largely overlaps with processing of non-painful interoceptive sensations (Legrain et al., 2011; Moseley et al., 2012), and in that painful stimulation is relayed through a central homeostatic pathway along with other visceral and somatic afferents signaling the disruption of homeostasis (Craig, 2003).

From an evolutionary perspective, fears promote an animal's chances of survival by helping to select a response appropriate for counteracting a perceived or anticipated threat (Ohman and Mineka, 2001). In this line of logic, interoceptive fear can have an adaptive advantage in urging a behavioral response to restore homeostasis or

Abbreviations: CP, cold pain; CPT, cold pressor test; EMG, electromyography; IAPS, International Affective Picture System; SAM, self-assessment manikin; VAS, visual analog scale.

* Corresponding author. Tel.: + 32163260 29; fax: + 3216326144 .

E-mail addresses: Erik.Ceunen@ppw.kuleuven.be (E. Ceunen),

Johan.Vlaeyen@ppw.kuleuven.be (J.W.S. Vlaeyen), Ilse.VanDiest@ppw.kuleuven.be (I. Van Diest). prevent its disruption. However, interoceptive fear in the absence of a 57 real threat may paradoxically lead to over-perception of bodily sensa- 58 tions and to excessive physical symptom reports.

Functional disorders, anxiety disorders, and pain related disorders, 60 affect a significantly large part of the population. In all of these disorders 61 interoceptive fears play a key role, implying that the advancement of 62 both clinical and fundamental knowledge on interoceptive fear is of 63 utmost importance. A body of literature as well as a number of labora- 64 tory studies imply that the etiology and maintenance of such disorders 65 is due to associative learning processes (Acheson et al., 2007; Bouton et al., 2001; De Peuter et al., 2011; Mayer, 2000; Meulders et al., 2011; Pappens et al., 2013). Because of interoceptive fear conditioning, origi- 68 nally benign sensations can elicit fear responses, when in the past 69 these benign sensations have preceded an aversive interoceptive 70 sensation.

Although interoceptive fear conditioning has a strong pedigree in 72 the understanding of the aforementioned disorders, relatively little 73 research has elaborated on the basic fear response topography to inter- 74 oceptive stimulations used in the laboratory. Therefore, the major aim 75 of the current study was to document unconditioned fear responding 76 to such interoceptive stimulations. We made a selection of stimuli 77 frequently used in experimental paradigms on pain (e.g., Helsen et al., 78 2011) and dyspnea (Acheson et al., 2007; Pappens et al., 2011), namely 79 cold pain, inhalation of $\mathrm{CO}_{2}$-enriched air, and loaded breathing. We 80 selected these particular stimuli because a limited body of literature 81 on startle in response to these stimuli is already available, although as 82 yet no design has presented these three stimuli in comparable manners 83 within subjects. In this initial study, we limited ourselves to women: we 84 justify this choice given that psychosomatic complaints and disorders 85 
have a higher prevalence among women (Kroenke and Spitzer, 1998; Sar, 2010).

The potentiation - i.e. the relative increase in magnitude - of the eye blink component of startle is a well-validated and widely accepted measure of fear responding. An important question relating to the aim of the current study is whether the eye blink component of startle can provide a reliable indication of fear during aversive interoceptive stimulation. The startle reflex is modulated by the motivational system (Lang et al., 2000), and shows an increased amplitude when experienc-

Q14Q15 ing fear (Globisch et al., 1999; Hamm et al., 1997) or something which is Q16 otherwise unpleasant (Vrana et al., 1988). Affective modulation of the 97 startle reflex magnitude results from activation of a variety of structures 98 in which the amygdala plays a pivotal role. This modulatory effect of the 99 motivational neurocircuitry on the eye blink motor reflex is described in more detail in the literature (e.g., Davis, 2006; Lang et al., 1998; Misslin, 2003). Although potentiation of startle following manipulations that induce fear or unpleasantness is a robust finding, it has predominantly been tested using visual and auditory stimuli. In contrast, the few studies on startle in response to aversive interoceptive stimulation present a more complicated and as yet inconclusive picture of findings.

With regard to thermal pain stimulation, findings are somewhat equivocal. For phasic heat pain, it appears that stimulation of short duration evokes startle potentiation (Crombez et al., 1997), whereas stimulation of a longer duration does not (Horn et al., 2012, in press). For cold pain, there is an overall reduction when averaging startle amplitudes delivered at different times during a prolonged stimulation (Tavernor et al., 2000), whereas such reduction may not be evident at individual time points (De Peuter et al., 2009). Lovallo (1975) describes that pain in response to the cold pressor test (CPT) does not keep rising progressively as time of immersion increases, a finding which may explain why startle probes at particular time intervals are not reduced.

Regarding dyspnea, findings from several studies conducted in our research group strongly suggest that dyspnea induced by the inhalation of $\mathrm{CO}_{2}$-enriched air is associated with an inhibition of the startle reflex (De Peuter et al., 2009; Pappens et al., 2012; Van Diest et al., 2009b). Paradoxically, when dyspnea is induced by loaded breathing - a mechanical stimulus creating respiratory resistance - startle potentiation is evident when the stimulus is light (near perceptual threshold level), but absent when a respiratory load of higher (moderate) intensity is administered (Pappens et al., 2010). This is paradoxical, because self-report measures as well as skin conductance indicated that the higher load was more aversive and arousing than the light load.

Possible mechanisms for these findings have been suggested by their respective authors, and will be reviewed in the Discussion section. Regardless of the mechanism responsible for the apparently atypical startle pattern found in earlier studies documenting startle responding to the $\mathrm{CPT}$, inhalation of $\mathrm{CO}_{2}$-enriched air, and loaded breathing, it seems that startle within one type of stimulus is inversely correlated with unpleasantness (Pappens et al., 2010). The following parsimonious conclusions could be made: (a) these types of aversive interoceptive stimulation are associated with a reduction in startle rather than potentiation. (b) As dyspneic stimuli become more aversive as time progresses, it could be expected that startle responsivity decreases overall as the duration of dyspneic interoceptive stimulation increases. However, (c) startle in response to painful peripheral hypothermic stimulation may be an exception in that pain fluctuates over the course of time, and accordingly, startle may not necessarily decrease linearly over time.

To test these hypotheses, in the current study we subjected these earlier findings to a novel experimental paradigm, allowing for a within-subject comparison of unconditioned defensive responding to these three types of sustained, aversive interoceptive stimulation. The primary aim of this study was to shed light on the startle response over time to three types of stimulation. Eye blink startle responses were studied during 90 s periods of cold pain, inhalation of $\mathrm{CO}_{2}$-enriched air, and loaded breathing. In contrast to the studies of Pappens et al. (2010, 152 2011), which applied loads for only one inspiration, the continued stim- 153 ulation allowed for testing our assumption that startle declines linearly 154 during the course of dyspneic stimulation. Since we did not expect 155 potentiation but rather a reduction in startle, it was important to 156 make sure any reduction in startle wouldn't be due to habituation. 157 Therefore it was important to have a design which would allow us to 158 statistically correct for habituation-bound decrease in startle. For this 159 reason, startles were measured during a baseline phase prior to the 160 stimulus phase, and during a recovery phase following the stimulus 161 phase, so that a best fit line could be calculated which would filter out 162 the effects of habituation. Another new element in the current experi- 163 ment was that respiratory loads were applied both during inspiration 164 and expiration, so that startle eliciting probes would always be admin- 165 istered during actual stimulation.

To test the general conclusions we made earlier, we respectively 167 expected to observe:

(a) A reduced startle blink magnitude during aversive interoceptive 169 stimulation, as compared to prior and following an aversive in- 170 teroceptive stimulus. Given our design, this would correspond 171 to a reduction of startle during stimulus phase as compared to 172 baseline and recovery phase.

173

(b) For both dyspneic stimuli, we hypothesized a progressive reduc- 174 tion of the startle magnitude during the stimulus phase, as 175 unpleasant dyspneic stimuli have been shown earlier to be asso- 176 ciated with reduced startle responding, and as these stimuli 177 are thought to become progressively more unpleasant as time 178 since the onset increases.

(c) For the CPT, we expected a quadratic response pattern during 180 the stimulus phase, given that the overall average of multiple 181 startle responses is associated with a reduction in amplitude 182 (Tavernor et al., 2000) while no such reduction has been evident 183 during the 30 to 60 second period following stimulus onset (De 184 Peuter et al., 2009), the latter which is perhaps due to the fluctu- 185 ations in pain sensations during cold stimulation.

186

In line with earlier findings, it was expected that all stimuli would be 188 Q25 scored as unpleasant rather than pleasant, that these stimuli would in- 189 duce some self-perceived arousal as opposed to complete calm, leading 190 to sub-maximal levels of feelings of dominance, and to induce some 191 fear.

\section{Materials and methods}

\subsection{Participants}

Thirty-six female psychology freshmen (mean age: $19 \mathrm{y} /$ old) partic- 195 ipated in return for course credit. Exclusion criteria were pregnancy, 196 presence or history of cardiovascular disease, pain-related conditions, 197 or respiratory disease. Participants were randomly assigned to one of 198 six orders of stimulus presentation - stimulus presentation orders 199 were counterbalanced. The study protocol was approved by the Ethics 200 Committee of the Department of Psychology in accordance with the 201 Declaration of Helsinki (World Medical Association, 1997); prior to par- 202 ticipation, all subjects read and signed an informed consent with infor- 203 mation about the sensations that could possibly follow from exposure 204 to the stimuli, a guarantee about anonymity, and that participation 205 was voluntary and could be terminated at any point in time without 206 loss of the promised course credit.

\subsection{Stimuli and apparatuses}

The cold pressor test (CPT) was used as a cold pain (CP) stimulus. 210 The CPT consisted of a Plexiglas water basin (Julabo®, Seelbach, 211 
Germany), model 19A, containing a type FT200 cooler and type ED water circulator. During the CPT, participants were requested to immerse their right hand to the wrist in this water-filled basin positioned on the right-hand side of their seat. The water with a constant temperature of $6{ }^{\circ} \mathrm{C}$ was circulated to prevent buildup of warmer water around the hand; the hand was to be held in the cold water for a duration of $90 \mathrm{~s}$. Pain at this temperature is experienced as intense, very cold and deep, and produces sympathetic autonomous responses (Casey et al., 1996). Participants were explicitly told beforehand that this was not a pain tolerance test and were informed about the duration the hand had to be held in the cold water; this information was provided with the purpose of discouraging participants to withdraw their hand prematurely, although they were free to withdraw their hand at any time. In the $90 \mathrm{~s}$ prior to and the $90 \mathrm{~s}$ following the CPT, participants immersed their hand in a stainless steel water basin, model FBATH18 (Techne®, Staffordshire, United Kingdom), with the water having a constant temperature of $30^{\circ} \mathrm{C}$ and circulating by means of the TE-10D Tempette ${ }^{\circledR}$ thermo regulator and circulator. Immersing the hand in water of $30^{\circ} \mathrm{C}$ prior and following the CPT was intended to create equal conditions for everyone during the experiment. The two approximately equally sized water basins - one cold and one lukewarm - were purposefully chosen for their visual distinctiveness as to prevent subjects from immersing their hand in the wrong basin at the wrong time.

\subsection{2. $\mathrm{CO}_{2}$}

A gas mixture of $\mathrm{CO}_{2}$ enriched air, with a proportion of $7.5 \% \mathrm{CO}_{2}$, $21 \% \mathrm{O}_{2}$ and $71.5 \% \mathrm{~N}_{2}$ was administered for a duration of $90 \mathrm{~s}$ to induce sensations of dyspnea. The decompressed gas mixture was contained in a meteorological balloon and connected to the inspiratory port. Apart from dyspneic sensations and altered respiratory behavior, 7.5\% $\mathrm{CO}_{2}$ enriched air can elicit (transient) sweating, feelings of warmth, and dizziness (Devriese et al., 2006; Stegen et al., 1998). Effects of $\mathrm{CO}_{2}$ inhalation are thought to be cumulative, with less effect on the first few breaths. Similarly, after termination of $\mathrm{CO}_{2}$ administration, the blood $\mathrm{pH}$ level gradually - not instantaneously - returns to its normal level, an effect which is referred to as washout.

\subsubsection{Resistive loads}

Resistive loads require extra effort from the respiratory muscles the diaphragm and intercostals - during breathing, in order to maintain flow rate and volume. The accompanying sensation is comparable to breathing through a narrow tube and resembles dyspneic sensations experienced in COPD, asthma and other types of obstructed breathing (Younes, 1995). Unlike $\mathrm{CO}_{2}$ administration, loaded breathing can be noticed from the first breath. Prolonged loaded breathing may additionally have some cumulative effects, as respiratory muscles can become fatigued. In the current study, two resistive loads were used: one was applied to the inspiratory valve, and one to the expiratory valve. Applying both an inspiratory and expiratory load on breathing ensured that stimulation was continuously unpleasant as it was for the other two stimuli, and that the startle eliciting probe would always fall during actual stimulation. Both loads were of an intensity of $1.96 \mathrm{kPa} \mathrm{l}^{-1} \mathrm{~s}$, an intensity rated as unpleasant (Pappens et al., 2010).

\subsubsection{Breathing apparatus}

Throughout the experiment - except during self-report - participants breathed through a mouthpiece while wearing a nose clip. The mouthpiece was fitted on a microbial filter, which in its turn was connected to a non-rebreathing valve to ensure that inspiratory and expiratory air remained separated. The inspiratory and expiratory port of the non-rebreathing valve were both connected to a manual directional control three-way $\mathrm{T}$-shape ${ }^{\mathrm{TM}}$ stopcock-type ${ }^{\mathrm{TM}}$ valve (Hans Rudolph, Inc., series 2110) by means of a vinyl tube (inner diameter $3.5 \mathrm{~cm}$; length $100 \mathrm{~cm}$ ). In the loaded breathing trial, the valves allowed easy switching between loaded and unloaded breathing. In the $\mathrm{CO}_{2}$ inhalation trial, the three-way valve allowed easy switching between 275 breathing room air and $\mathrm{CO}_{2}$ enriched air on the inspiratory side.

\subsubsection{Eye blink startle response}

Electromyographic (EMG) activity of the left orbicularis oculi 278 muscle as response to acoustic startle probes (95 dB) was measured 279 by the placement of three electrodes filled with high conductivity 280 Microlyte electrolyte gel. One electrode was placed perpendicular 281 under the pupil when the eye was in forward gaze, the second 282 approximately 1 to $2 \mathrm{~cm}$ lateral to the first (center-to-center) following 283 the curvature of the eye, and one signal ground electrode was placed on 284 the center of the forehead. All sites were first cleaned with alcohol to 285 reduce inter-electrode resistance. The raw signal was amplified by a 286 Coulbourn isolated bioamplifier with bandpass filter (LabLinc v75-04) 287 with a $90 \mathrm{~Hz}$ high pass filter. This signal was routed to a Coulbourn 4288 channel integrator (LabLinc v76-24), which rectified and smoothed 289 the signal online with a time constant of $20 \mathrm{~ms}$. The EMG signal was 290 sampled at $1000 \mathrm{~Hz}$ starting $500 \mathrm{~ms}$ prior to the onset of the auditory 291 startle probe, until $1000 \mathrm{~ms}$ after probe onset.

\subsubsection{Software}

All signals were transmitted through a 16-Bit National Instruments 294 PCI-6221 data acquisition card (National Instruments, Austin, Texas) 295 to a computer. Affect 4.0 software (Spruyt et al., 2010) was used for $296 \mathbf{Q 2 9}$ running the experiment as well as for data acquisition. A modular 297 script-based program named PSychoPHysiological Analysis and abbre- 298 viated as PSPHA (De Clercq et al., 2006) was used to handle the 299 Q30 recorded signals offline and to extract the relevant parameters neces- 300 sary for statistical analysis.

\subsubsection{Self-report measures}

At the end of each trial a computerized 9-point scale of the language- 303 free self-assessment manikin (SAM-scale, Bradley and Lang, 1994) was 304 administered to retrospectively rate the mean valence (unpleasant $=1 ; 305$ pleasant $=9$ ), arousal $($ calm $=1$; excited $=9$ ), and dominance 306 (lack of control $=1$, sense of control $=9$ ) felt during the 90 second 307 stimulus. Before proceeding to the next trial, subjects were requested 308 to indicate their fear as experienced during the stimulus period on a 309 computerized horizontal visual analog scale (VAS; $0=$ not at all 310 scared; $100=$ extremely scared).

\subsection{Procedure}

Upon arrival, the experimenter led the participants into the experi- 313 mental room where he provided them an informed consent. The 314 informed consent briefly mentioned all stimuli, as well as the sensations 315 each stimulus may respectively elicit, and that any sensations felt were 316 without harm and were of a transient nature. Participants were request- 317 ed to read through the consent before agreeing to sign it. After signing, a 318 brief questionnaire of medical history in relation to exclusion criteria 319 (see Section 2.1) was provided. Next, electrodes were attached - Q31 Q32 subjects were informed that these were meant for measuring phy- 321 siological responses, albeit without further specifications. The experi- 322 menter verbally went through the experimental procedure, and then 323 placed headphones on the participant. Participants were requested to 324 put on the nose clip and breathe through the mouthpiece, and told to 325 keep their eyes fixated in the direction of the computer screen. Partici- 326 pants sat upright (not reclined) throughout the entire experiment and 327 lights remained on (not dimmed). Prior to initiation of the experimental 328 manipulations, the experimenter left and went to the operator room, 329 adjacent to the room where participants were left alone throughout 330 the entire experiment; the experimenter remained in the operator 331 room until the experiment was over.

Prior to each trial, 10 acoustic startle probes were administered to 333 habituate participants to the startle probe. Habituation to the probes 334 was done because startle responses tend to be amplified at the initial 335 
presentation of the acoustic probes due to their novelty. During habituation the interval between probes varied from 19 to $21 \mathrm{~s}$. After startle probe habituation, a trial started off with a baseline phase of $90 \mathrm{~s}$ where subjects breathed through a mouthpiece, fixated their eyes on a computer screen, and received three startle probes at unpredictable times, one during the first, one during the second and one during the last $30 \mathrm{~s}$. Additionally, in the CPT trial, subjects immersed their hand in lukewarm water during baseline. The second phase was the stimulus phase during which either of the three stimuli - cold water, $\mathrm{CO}_{2}$-enriched air, or loaded breathing - was administered. During this phase, again there were three startle probes at variable times - one during the first $30 \mathrm{~s}$, one during the second, and one during the last. The third phase is referred to as the recovery phase, and was identical to the baseline phase, except in that it followed - instead of preceded - the stimulus phase. After recovery, subjects were free to release the mouthpiece while they filled out the self-report scales, before proceeding to the next trial. In total there were three trials, and only one (continuous) stimulus was presented per trial, during the stimulus phase. Avoiding repeated presentation of stimuli ensured that potential learning behavior and alteration of responses due to recent exposure was minimized. At the end of the experiment, subjects were fully debriefed.

\subsection{Data analysis}

Eye blink startle EMG responses were calculated by subtracting the mean value from the 0 to $20 \mathrm{~ms}$ following probe onset from the peak value found in the 21 to $175 \mathrm{~ms}$ time window following probe onset. Excluding startle measured during habituation, there were 27 remaining data points per subject. Data points where there was already blink activity at the onset of startle probe presentation were rejected $(<10 \%)$ as recommended by Blumenthal et al. (2005). The maximum percentage of missing data points for a single subject was just under $26 \%$, while the mean number of missing data points per person was just over $7 \%$. After removing rejected values, startle amplitudes were transformed to T-scores for each individual, which is a common procedure (see Blumenthal et al., 2005). The reason for this transformation was that we were interested in overall intraindividual differences in response to the different phases and probe delivery times, and not in interindividual differences in response amplitude. Having obtained individual T-scores, missing data were replaced by the mean startle amplitude in response to the same probe of those people who had received all stimuli in the same order. We did this to rule out effects of stimulus presentation order on amplitude. Once missing data were replaced, the data were detrended by using individual regression models with probe order as the predictor (Lüthy et al., 2003). Using this method, the mean of a best fit line was subtracted from the actual T-score. Unless this method is applied, magnitudes in our design are generally higher during baseline, and lower during recovery, simply because startle magnitudes continue to decline linearly, even after initial habituation. By removing this linear reduction in magnitude, the magnitudes at each point in time across the three phases become better comparable, and the differences in amplitude that remain are more likely due to the sensations at that moment of prolonged stimulation.

The detrended data were then entered into repeated measures ANOVA's, with trial type (CPT, $\mathrm{CO}_{2}$ or load trial), phase (baseline, stimulus, or recovery), and startle probe timing (1st $30 \mathrm{~s}, 2$ nd $30 \mathrm{~s}$, or last $30 \mathrm{~s}$ ) as within subject variables. In order to test our first hypothesis that startle would be reduced during aversive interoceptive stimulation as compared to baseline and recovery phase, we performed a polynomial quadratic contrast for the effect of phase on all data points. In order to test our second hypothesis that startle would progressively decrease during prolonged dyspneic stimulation, we performed a polynomial linear contrast on the effect of startle probe timing on the data points obtained during the stimulus phase of both dyspneic stimuli.
And finally, in order to test our third hypothesis that startle in response 400 to the CPT would show a reduction in amplitude overall, except during 401 the 30 to $60 \mathrm{~s}$ following the onset, we performed a polynomial quadrat- 402 ic contrast on the data points obtained during the stimulus phase of CPT. 403

The SAM scores for valence of the three stimuli were compared 404 using a one-way repeated measures ANOVA. The same analysis was 405 done for the SAM scores on arousal as well as for dominance levels 406 and VAS state anxiety scores compared in response to the three 407 stimuli.

\section{8}

An $\alpha$-level of .05 was set for statistical significance. Analyses were 409 done using the STATISTICA version 10 software package and the 410 means and standard deviations displayed in Table 1 were obtained 411 using the JMP 9 software package.

\section{Results}

\subsection{Eye blink EMG}

To test our first hypothesis that startle is reduced during intero- 415 ceptive stimulation (all three stimuli), a univariate test of significance 416 for planned comparisons of least square means for the effect of PHASE 417 confirmed the existence of a quadratic contrast, $F(1,35)=6.19,418$ $\mathrm{p}<.05$, meaning that startle dropped from baseline phase to stimulus 419 phase, and rose again from stimulus phase to recovery phase (see 420 Fig. 1a). To test our second hypothesis that dyspneic stimuli lead to 421 a progressive decrease in startle responding, another test for planned 422 comparisons was performed for the effect of startle probe timing 423 during stimulus phase of both dyspneic stimuli, and found a linear 424 decrease in startle magnitude, $F(1,35)=4.20, \mathrm{p}<.05$ (see Fig. $1 \mathrm{~b}$ ). In 425 contrast, the effect of startle probe timing during the stimulus phase 426 of the CPT displayed a quadratic pattern, $F(1,35)=4.68, \mathrm{p}<.05$. That 427 is, during the stimulus phase where the CPT was administered, there 428 was an initial reduction in startle amplitude, followed by an increase 429 in amplitude, which was in its turn followed by a decrease in amplitude 430 again (see Fig. 1c).

\subsection{Self-report}

As evident from Table 1, the three stimuli evoked similar levels of 433 arousal, dominance, and fear. The only significant difference between 434 the stimuli was in perceived valence, $F(2,70)=5.52, \mathrm{p}<.01$, with 435 Tukey-Kramer post-hoc tests indicating that $\mathrm{CP}$ was rated as more 436 unpleasant than both $\mathrm{CO}_{2}$ inhalation $(\mathrm{p}=.01)$ and loaded breathing 437 $(\mathrm{p}<.05)$.

\section{Discussion}

439

The current study aimed to elucidate the startle response pattern $440 \mathbf{Q 3 3}$ during aversive interoceptive stimulation, and used a sample of 36441 young adult females to do so. To date affective modulation of startle 442 has almost exclusively been studied using visual and auditory stimuli, 443

Table 1 $\mathrm{t} 1.1$ Means and standard deviations for valence, arousal, dominance, and fear experienced t1.2 during stimulation.

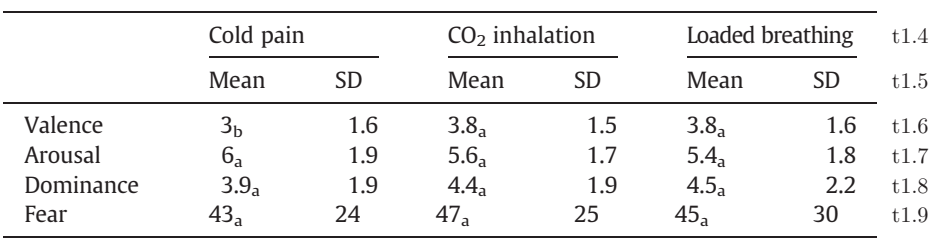

Note. Valence, arousal, and dominance all ranged from 1 to 9 , respectively unpleasant t1.10 versus pleasant, calm versus excited, and a lack of control versus a sense of control. t1.11 Fear ranged from 0 to 100 , respectively from not at all scared to extremely scared. t1.12 Means in the same row which share a subscript are not significantly different from t1.13 one another according to Tukey-Kramer post-hoc tests. 


\section{a) Overall startle magnitudes}
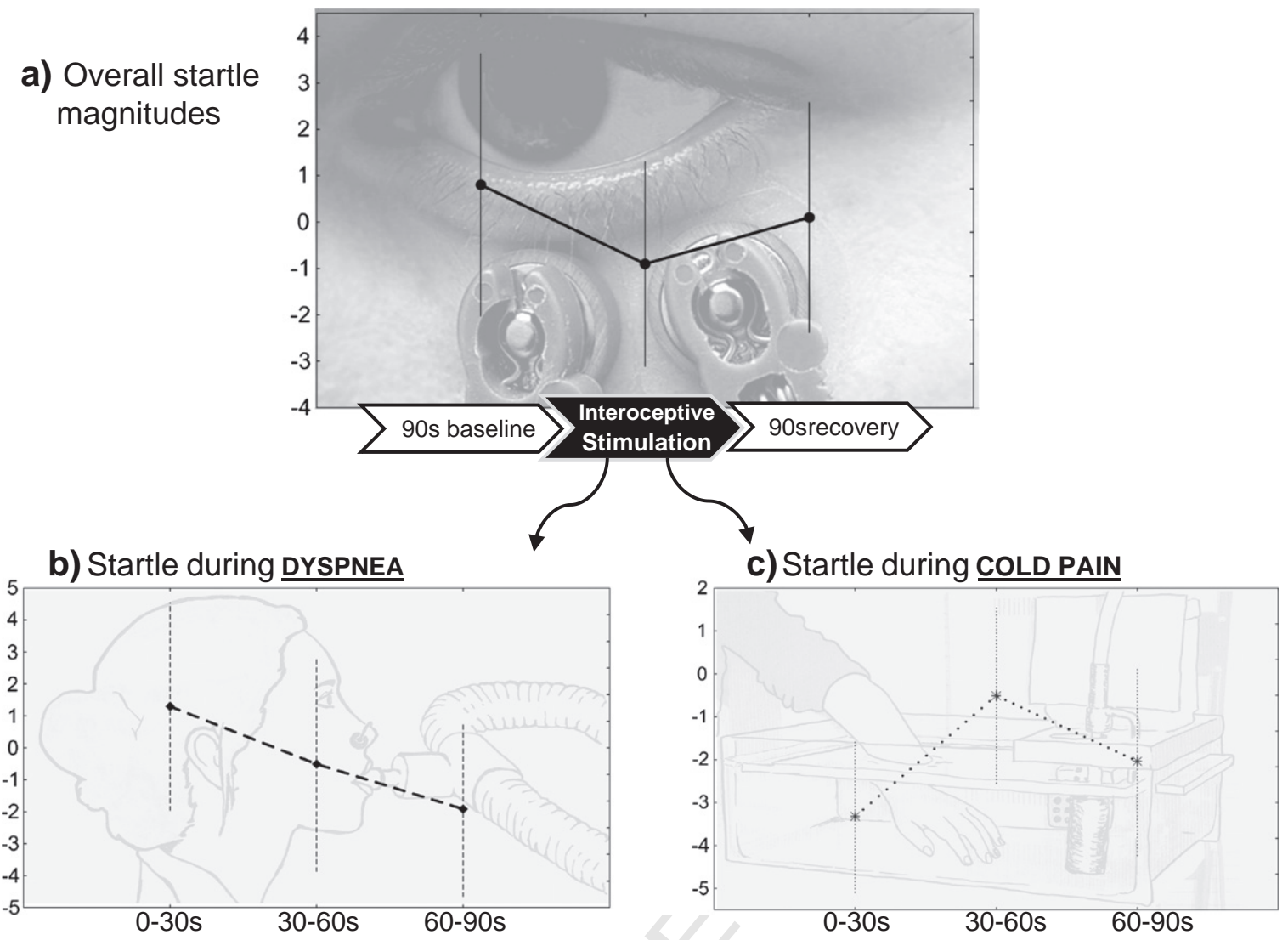

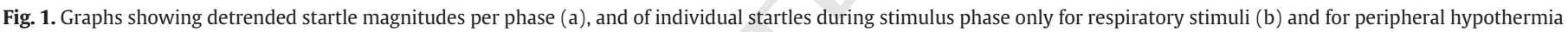
(c). Values are presented as magnitude means \pm 0.95 confidence intervals

mental imagery, and sometimes using anticipation of aversive interoceptive sensations (e.g., Lang et al., 2011; Melzig et al., 2008). However, reports on startle during aversive interoceptive stimulation are still very scarce. In this initial study on within-subject responses to different types of interoceptive stimulation, two respiratory stimuli commonly used in studies on dyspnea and fear, and one cold stimulus commonly used in research on pain were presented to participants. In order to effectively document startle not as a conditioned response, but as an unconditioned response, all stimuli were administered only once, which necessitated that they be administered for a relatively prolonged duration in order to allow for the administration of multiple startle probes.

The findings from our current study are in accordance with the scarce amount of previously published data, in that startle responding to these three interoceptive stimuli is reduced overall. A new insight from the current study is the presence of a linear decrease of startle responding in face of dyspneic stimulation, and a non-linear, quadratic startle response pattern during the CPT.

The overall reduction of startle for all three stimuli is evident despite that all three stimuli are rated as fearful, unpleasant, arousing, and associated with sub-maximal levels of dominance. Although the ratings of unpleasantness are not at the extreme end of the valence-scale, an earlier study of Pappens (2010) found that the intensity of respiratory loaded breathing which we also used in the current study, was more aversive than aversive pictures from the International Affective Picture System (IAPS). Moreover, the $\mathrm{CO}_{2}$ inhalation in the current study was equally aversive as loaded breathing, and $\mathrm{CP}$ was even more aversive. That participants in the current study refrained from filling in the extremes of the valence and fear scales does not indicate the stimuli were ineffective in inducing unpleasantness or fear. Rather, we argue this underreport to be due to the lack of milder unpleasant stimuli (e.g., unpleasant pictures), and the anticipation that a potentially 475 more aversive stimulus might be presented in a subsequent trial (re- 476 quiring that the extremes of the scale need to remain unused until 477 then). Though we did not let subjects rate the baseline and recovery 478 phases, right after the experiment was over subjects informally 479 informed the experimenter that those phases were dull (they had to 480 stare at a fixation cross and knew no stimuli would be presented during 481 those phases), thus ruling out that the affective tone was constantly 482 negative.

From the perspective of the emotional priming model, which 484 posits that startle magnitude should be greater when the aversive 485 motivational system is active (Lang et al., 1998), the overall reduction 486 in startle is puzzling. Although the few previous studies that found 487 similar results forwarded a number of explanations, currently there 488 is no satisfactory answer to the mechanisms underlying this unusual 489 response pattern. Nevertheless, based on prior explanatory specula- 490 tions, some suggestions for future research can be made.

One speculation that has been made earlier, is that the reduction 492 in startle responding is due to the interoceptive nature of the stimuli 493 (Pappens et al., 2010), implying that aversive interoceptive stimulation 494 of any kind would fail to evoke potentiation. Although the current study 495 did not find any counterevidence for this claim, further research with 496 other types of interoceptive stimulation is necessary in order to truly 497 falsify this claim. Moreover, resorting to the interoceptive nature of 498 the stimuli as an explanation for the unusual startle response, requires 499 a predefined and well-outlined working definition of interoception, 500 given that consensus on its definition is lacking, in particular with 501 regard to the 'outer boundaries' of the concept (Dworkin, 2007). 502

Another explanation forwarded by Pappens et al. (2010) is that 503 according to the defense cascade model (Lang et al., 1997), startle po- 504 Q37 tentiation should no longer be evident during the circastrike (fight/ 505 
506 flight) phase of defensive responding, despite aversiveness of stimulation (e.g., Low et al., 2008; Richter et al., 2012). This circastrike phase of defensive responding is distinct from earlier defensive phases, not only in startle responding and threat imminence, but also in autonomous responses such as heart rate, skin conductance, and presumably in respiration as well (Van Diest et al., 2009a). In order to test whether the startle response pattern in face of interoceptive stimuli might be due to activation of circastrike responding, inclusion of additional autonomous measures could theoretically provide further conclusive evidence. In practice however, many interoceptive stimuli, including the stimuli used in this experiment, elicit regulatory homeostatic responses, which may complicate interpretation of autonomous measures, making this hypothesis hard to test for at least a number of interoceptive stimuli.

Finally, orientation of attention to bodily processes has been speculated to be responsible for a reduction in responsiveness to auditory stimuli such as the startle probe (Pappens et al., 2012). This speculation could be tested by manipulating orientation of attention to bodily processes or to surrounding stimuli such as acoustic probes. To date, only one such study has been done and suggests orientation of attention inward may be responsible for a reduction in startle responding to respiratory loads (Pappens et al., 2011), but it remains unclear whether this could also explain startle in response to $\mathrm{CO}_{2}$ or the CPT. An alternative method to corroborate this explanation, is to include a measure of attention requiring subjects to indicate whether their attention was oriented predominantly at bodily sensations, predominantly at surrounding stimuli, or divided between both.

In the current study, these explanatory hypotheses were not extensively put to the test, as the primary aim was to describe, not explain the response pattern to the interoceptive stimuli we selected. Nevertheless, the present findings provide sufficient reason for taking these hypotheses and the methods to test them into account in future studies. Outlining the definition of interoception, testing startle in response to other forms of aversive interoceptive stimulation, inclusion of other psychophysiological measures in some instances, and manipulation and/or measures of orientation of attention are all potential avenues for future research, which may elucidate the mechanism responsible for the atypical startle patterns observed in the current and previous studies. Additionally, possible sex differences in the subjective experience and/or in the psychophysiological response pattern may require more attention in future studies, given that psychosomatic complaints are predominantly present in women (Kroenke and Spitzer, 1998; Şar, 2010). Until these issues are addressed in further studies, any explanatory hypotheses remain speculative at best. For now, we are left with only a descriptive model of startle to aversive interoceptive stimulation.

In this respect, it needs to be mention that the startle-by-startle analysis, a method usually rejected in favor of averaging magnitudes of startles delivered at different times, may actually provide additional insight into the pattern of responding over the course of time. The startle-by-startle analysis accounts for discrepancies between the study of Tavernor (2000) and an earlier study of ourselves (De Peuter et al., 2009); our current findings illustrate that although startle responding may be generally reduced following $\mathrm{CPT}$, it is not necessarily reduced at all points in time following the onset of this stimulus. The magnitude increase during the 30 to 60 second interval that we have found a second time now, warrants a startle-by-startle analysis in addition to the more common averaging method, especially when startles are administered during prolonged aversive stimulation. Moreover, further research on the CPT and its concomitant fluctuations of sensory discomfort over the course of time are necessary, as these sensory fluctuations may underlie the fluctuations in startle responding. Currently, such research is very limited (e.g., Davis and Pope, 2002).

In conclusion, the evidence for an unusual startle response pattern during interoceptive stimulation is becoming more substantial. Although it is commonly assumed that startle is potentiated during aversive emotional states including fear, an opposite pattern has been 572 found for a number of fearful interoceptive stimuli. A startle-by-startle 573 analysis suggests this to be dependent on subjective fearfulness which 574 generally increases following the onset of respiratory stimulation, but 575 presumably fluctuates for CP induced by the CPT. Further research is 576 needed to test this hypothesis more thoroughly, and to find out if the 577 results are specific to women, or whether they also apply to men. 578

\section{Acknowledgments}

This study was supported by the Odysseus Grant "The Psychology 580 of Pain and Disability Research Program" funded by the Research 581 Foundation-Flanders, Belgium (FWO Vlaanderen).

\section{References}

Acheson, D.T., Forsyth, J.P., Prenoveau, J.M., Bouton, M.E., 2007. Interoceptive fear con- 584 ditioning as a learning model of panic disorder: an experimental evaluation using 585 $20 \% \mathrm{CO}_{2}$-enriched air in a non-clinical sample. Behaviour Research and Therapy 45586 (10), 2280-2294. http://dx.doi.org/10.1016/j.brat.2007.04.008. Committee report: guidelines for human startle eyeblink electromyographic studies. 589 Psychophysiology 42 (1), 1-15. http://dx.doi.org/10.1111/j.1469-8986.2005.00271.x. 590

Bouton, M.E., Mineka, S., Barlow, D.H., 2001. A modern learning theory perspective on the 591 etiology of panic disorder. Psychological Review 108 (1), 4-32. http://dx.doi.org/ 592 10.1037//0033-295x.108.1.4.

Bradley, M.M., Lang, P.J., 1994. Measuring emotion - the self-assessment manikin and 594 the semantic differential. Journal of Behavior Therapy and Experimental Psychiatry 595 25 (1), 49-59. http://dx.doi.org/10.1016/0005-7916(94)90063-9.

Casey, K.L., Minoshima, S., Morrow, T.J., Koeppe, R.A., 1996. Comparison of human cere- 597 bral activation patterns during cutaneous warmth, heat pain, and deep cold pain. 598 Journal of Neurophysiology 76 (1), 571-581.

Craig, A.D.B., 2002. How do you feel? Interoception: the sense of the physiological con- 600 dition of the body. Nature Reviews Neuroscience 3 (8), 655-666. http://dx.doi.org/ 601 10.1038/Nrn894.

Craig, A.D.B., 2003. A new view of pain as a homeostatic emotion. Trends in Neurosci- 603 ences 26 (6), 303-307. http://dx.doi.org/10.1016/S0166-2236(03)00123-1. 604

Crombez, G., Baeyens, F., Vansteenwegen, D., Eelen, P., 1997. Startle intensification dur- 605 ing painful heat. European Journal of Pain 1 (2), 87-94 (doi: S1090380197900665 606 [pii]).

Davis, M., 2006. Neural systems involved in fear and anxiety measured with fear- 608 potentiated startle. American Psychologist 61 (8), 741-756. 609

Davis, K.D., Pope, G.E., 2002. Noxious cold evokes multiple sensations with distinct 610 time courses. Pain 98, 179-185.

De Clercq, A., Verschuere, B., De Vlieger, P., Crombez, G., 2006. Psychophysiological 612 analysis (PSPHA): a modular script-based program for analyzing psychophysiolog- 613 ical data. Behavior Research Methods 38 (3), 504-510. http://dx.doi.org/10.3758/ 614 BF03192805.

De Peuter, S., Ceunen, E., Van Diest, I., Van den Bergh, O., Vlaeyen, J.W.S., 2009. Eye-blink 616 Q42 startle response is potentiated by cold pressor pain but Inhibited by $\mathrm{CO}_{2}$-induced 617 breathlessness. Psychophysiology 46, S75-S75.

De Peuter, S., Van Diest, I, Vansteenwegen, D. Van den Bergh, O, Vlaeyen, JW S, 2011, 619 Pain-related Fear and Chronic Pain: Interoceptive Fear Conditioning as a Novel 620 Approach. 1-9.

Devriese, S., De Peuter, S., Van Diest, I., Van de Woestijne, K.P., Van den Bergh, O., 2006, 622 US-inflation in a differential odor-conditioning paradigm is not robust: relevance 623 for medically unexplained symptoms. Journal of Behavior Therapy and Experimen- 624 tal Psychiatry 37 (4), 314-332. http://dx.doi.org/10.1016/j.jbtep.2006.03.003. 625

Dworkin, B.R., 2007. Interoception. In: Cacioppo, J.T., Tassinary, L.G., Berntson, G.G. 626 (Eds.), Handbook of Psychophysiology. Cambridge University Press, Cambridge. 627

Furst, J.B., Cooper, A., 1970. Combined use of imaginal and interoceptive stimuli, in 628 desensitizing fear of Heart attacks. Journal of Behavior Therapy and Experimental 629 Psychiatry 1 (1), 87-89.

Globisch, J., Hamm, A.O., Esteves, F., Ohman, A., 1999. Fear appears fast: temporal 631 course of startle reflex potentiation in animal fearful subjects. Psychophysiology 632 36, 66-75.

Hamm, A.O., Cuthbert, B.N., Globisch, J., Vaitl, D., 1997. Fear and the startle reflex: blink 634 modulation and autonomic response patterns in animal and mutilation fearful 635 subjects. Psychophysiology 34, 97-107.

Helsen, K., Goubert, L., Peters, M.L., Vlaeyen, J.W.S., 2011. Observational learning and 637 pain-related fear: an experimental study with colored cold pressor tasks. The Journal 638 of Pain 12 (12), 1230-1239.

Horn, C. Blischke, Y, Kunz, M. Lautenbacher, S., 2012. Does pain necessarily have an 640 affective component? Negative evidence from blink reflex experiments. Pain 641 Research \& Management 17 (1), 15-24.

Horn, C., Schaller, J., Lautenbacher, S., in press. Investigating the affective component of 643 pain: No startle modulation by tonic heat pain in startle responsive individuals. 644 International Journal of Psychophysiology.

Kroenke, K., Spitzer, R.L., 1998. Gender differences in the reporting of physical and 646 somatoform symptoms. Psychosomatic Medicine 60 (2), 150-155. 
Lang, P.J., Bradley, M.M., Cuthbert, B.N., 1997. Motivated attention: affect, activation, and action. In: Lang, P.J., Simons, R.F., Balaban, M. (Eds.), Attention and Orienting: Sensory and Motivational Processes. Lawrence Erlbaum Associates, Inc., Mahway, New Jersey.

Lang, P.J., Bradley, M.M., Cuthbert, B.N., 1998. Emotion, motivation, and anxiety: brain mechanisms and psychophysiology. Biological Psychiatry 44, 1248-1263.

Lang, P.J., Davis, M., Öhman, A., 2000. Fear and anxiety: animal models and human cognitive psychophysiology. Journal of Affective Disorders 61, 137-159.

Lang, P.J., Wangelin, B.C., Bradley, M.M., Versace, F., Davenport, P.W., Costa, V.D., 2011 Threat of suffocation and defensive reflex activation. Psychophysiology 48 (3), 393-396. http://dx.doi.org/10.1111/j.1469-8986.2010.01076.x.

Legrain, V., Iannetti, G.D., Plaghki, L., Mouraux, A., 2011. The pain matrix reloaded: a salience detection system for the body. Progress in Neurobiology (93), 111-124. http://dx.doi.org/10.1016/j.pneurobio.2010.10.005.

Lovallo, W., 1975. The cold pressor test and autonomic function: a review and integration. Psychophysiology 12 (3), 268-282.

Low, A., Lang, P.J., Smith, J.C., Bradley, M.M., 2008. Both predator and prey emotional arousal in threat and reward. Psychological Science 19 (9), 865-873. http:// dx.doi.org/10.1111/j.1467-9280.2008.02170.x.

Lüthy, M., Blumenthal, T.D., Langewitz, W., Kiss, A., Keller, U., Schächinger, H., 2003. Prepulse inhibition of the human startle eye blink response by visual food cues. Appetite 41 (2), 191-195.

Mayer, E.A., 2000. The neurobiology of stress and gastrointestinal disease. Gut 47 (6), 861-869.

Melzig, C.A., Michalowski, J.M., Holtz, K., Hamm, A.O., 2008. Anticipation of interoceptive threat in highly anxiety sensitive persons. Behaviour Research and Therapy 46 (10), 1126-1134. http://dx.doi.org/10.1016/j.brat.2008.07.002.

Meulders, A., Vansteenwegen, D., Vlaeyen, J.W.S., 2011. The acquisition of fear of movement-related pain and associative learning: a novel pain-relevant human fear conditioning paradigm. Pain 152 (11), 2460-2469.

Misslin, R., 2003. The defense system of fear: behavior and neurocircuitry. Clinical Neurophysiology 33 (2), 55-66. http://dx.doi.org/10.1016/S0987-7053(03)00009-1.

Moseley, G.L., Gallace, A., Spence, C., 2012. Bodily illusions in health and disease: physiological and clinical perspectives and the concept of a cortical 'body matrix'. Neuroscience and Biobehavioral Reviews 36 (1), 34-46. http://dx.doi.org/10.1016/ j.neubiorev.2011.03.013.

Ohman, A., Mineka, S., 2001. Fears, phobias, and preparedness: toward an evolved module of fear and fear learning. Psychological Review 108 (3), 483-522. http:// dx.doi.org/10.1037//0033-295x.108.3.483.

Pappens, M., Van den Bergh, O., De Peuter, S., Bresseleers, J., Vansteenwegen, D., Van Diest, I., 2010. Defense reactions to interoceptive threats: a comparison between loaded breathing and aversive picture viewing. Biological Psychology 84 (1) 98-103. http://dx.doi.org/10.1016/j.biopsycho.2010.02.006.

Pappens, M., Van den Bergh, O., Van Diest, I., 2011. Dyspnea and fear: a psychophysiological analysis. International Journal of Psychophysiology.
Pappens, M., De Peuter, S., Vansteenwegen, D., Van den Bergh, O., Van Diest, I., 2012. 693 Psychophysiological responses to $\mathrm{CO}_{2}$ inhalation. International Journal of Psycho- 694 physiology. http://dx.doi.org/10.1016/j.ijpsycho.2012.01.008.

Pappens, M., Van den Bergh, O., Vansteenwegen, D., Ceunen, E., De Peuter, S., Van Diest, 696 I., 2013. Learning to fear obstructed breathing: comparing interoceptive and 697 exteroceptive cues. Biological Psychology 92 (1), 36-42. http://dx.doi.org/10.1016/ 698 j.biopsycho.2011.05.004.

Richter, J., Hamm, A.O Pané-Farré, CA Gerlach, A.L., Gloster, A.T.,Wittchen, H.-U., 700 2012. Dynamics of defensive reactivity in patients with panic disorder and agora- 701 phobia: implications for the etiology of panic disorder. Biological Psychiatry 72702 (6), 512-520. http://dx.doi.org/10.1016/j.biopsych.2012.03.035. 703

Sar, V., 2010. Medically unexplained symptoms in women, In: Kohen, D. (Ed.), Oxford 704 Textbook of Women and Mental Health, 1st ed. Oxford University Press, New York, 705 pp. 254-261.

Shear, M.K., Brown, T.A., Barlow, D.H. Money, R., Sholomskas, D.E., Woods, S.W. 1997. 707 Multicenter collaborative panic disorder severity scale. The American Journal of 708 Psychiatry 154 (11), 1571-1575.

Spruyt, A., Clarysse, J., Vansteenwegen, D., Baeyens, F., Hermans, D., 2010. Affect 4.0: a 710 free software package for implementing psychological and psychophysiological 711 experiments. Experimental Psychology 57 (1), 36-45. http://dx.doi.org/10.1027/ 712 1618-3169/A000005.

Stegen, K., Neujens, A., Crombez, G. Hermans, D., Van de Woestijne, K.P., Van den 714 Bergh, O., 1998. Negative affect, respiratory reactivity, and somatic complaints in 715 a $\mathrm{CO}_{2}$ enriched air inhalation paradigm. Biological Psychology 49 (1-2), 109-122. 716

Tavernor, S.J., Abduljawad, K.A.J., Langley, R.W., Bradshaw, C.M., Szabadi, E., 2000. Effects 717 of pentagastrin and the cold pressor test on the acoustic startle response and pupillary 718 function in man. Journal of Psychopharmacology 4 (14), 387-394. http://dx.doi.org/ 719 10.1177/026988110001400407.

Van Diest, I. Bradley, M.M. Guerra, P., Van den Bergh, O., Lang PJ. 2009a. Fear-conditioned 72 respiration and its association to cardiac reactivity. Biological Psychology 80 (2), 722 212-217. http://dx.doi.org/10.1016/j.biopsycho.2008.09.006.

Van Diest, I., Pappens, M., Ceunen, E., De Peuter, S., Vansteenwegen, D., Van den Bergh, O., 724 2009b. Startle inhibition to interoceptive aversive stimulation. Annual meeting - 725 Society for Psychophysiological Research. Berlin, 21-24 October. Psychophysiology 726 46 (S1), s17.

Vrana, S.R., Spence, E.L., Lang, P.J., 1988. The startle probe response: a new measure of 728 emotion? Journal of Abnormal Psychology 97 (4), 487-491. http://dx.doi.org/ 729 10.1037/0021-843X.97.4.487.

World Medical Association, I, 1997. World Medical Association Declaration of Helsinki 731 - recommendations guiding physicians in biomedical research involving human 732 subjects - adopted by the 18th World Medical Assembly Helsinki, Finland, June, 733 1964. Cardiovascular Research 35 (1), 2-3.

Younes, M. 1995. Mechanisms of respiratory load compensation, In: Dempsey, J.A., 735 Pack, A.I. (Eds.), Regulation of Breathing, 2nd ed. Marcel, Dekker, Inc., New York, 736 pp. 867-922. 